\title{
The microbiome of the pelagic tunicate Dolioletta gegenbauri: a potential link between the grazing and microbiala
}

\author{
Tiago Pereira ${ }^{1}$, Tina Walters ${ }^{2}$, Hisham El-Shaffey ${ }^{3}$, Holly Bik $^{1}$, and Marc Frischer ${ }^{2}$ \\ ${ }^{1}$ University of Georgia \\ ${ }^{2}$ Skidaway Institute of Oceanography \\ ${ }^{3}$ North Carolina State University at Raleigh
}

August 1, 2022

\begin{abstract}
Bloom-forming marine gelatinous zooplankton, including the pelagic tunicate Dolioletta gegenbauri, occur circumglobally and have the potential to significantly influence the structure of pelagic marine food webs and biogeochemical cycling through interactions with microbial communities. Using targeted metabarcoding (16S rRNA genes recovering Bacteria/Archaea) and qPCR approaches associated with laboratory-based feeding experiments, we characterized patterns in doliolid gut microbiomes and microbial communities associated with doliolid fecal pellets and the surrounding seawater. The characterization of starved doliolids provides the first description of the doliolid gut microbiome. At the highest taxonomic levels, doliolid-associated bacterial communities are characteristic of marine bacterioplankton communities around the globe and were dominated by representatives of six major bacterial groups including Gammaproteobacteria, Alphaproteobacteria, Cyanobacteria, Planctomycetes, Bacteroidia and, Phycisphaerae. Comparison between sample types, however, revealed distinct patterns in diversity and biomass supporting the hypothesis that through their presence and trophic activity, doliolids influence the structure of pelagic food webs and biogeochemical cycling in subtropical continental shelf systems where doliolid blooms are common. Bacteria associated with starved doliolids (representative of the resident doliolid gut microbiome) possessed distinct communities, supporting the hypothesis that doliolids possess a unique but low diversity, low biomass microbiome optimized to support a detrital trophic mode. Among potential core microbiome taxa, the genera Pseudoalteromomas and Shimia were the most abundant, similar to patterns observed in other marine invertebrates. Exploratory bioinformatic analyses of predicted functional genes suggest that doliolids, via their interactions with bacterial communities, may affect important biogeochemical processes including nitrogen, sulfur, and organic matter cycling.
\end{abstract}

\section{INTRODUCTION}

Marine gelatinous zooplankton, including the mucus-feeding pelagic tunicates (appendicularia, pyrosomes, salps, and doliolids), occur circumglobally and play a central role in marine planktonic food webs (Alldredge \& Madin, 1982; Conley et al., 2018; Frischer et al., 2021). Our understanding of the ecological role of these fragile species is limited, however, primarily due to methodological challenges that limit the ability to observe, sample, and culture them (Walters, Gibson, et al., 2019). Because their life histories typically involve alternating sexual and asexual stages, pelagic tunicates are capable of rapid reproduction that can lead to bloom formation and that likely significantly influence the structure of pelagic marine food webs and biogeochemical cycling (Deibel, 1998; Frischer et al., 2021; Walters, Lamboley, et al., 2019). For example, pelagic tunicates within the order Doliolida (including the species Dolioletta gegenbauri) frequently form massive blooms on most of the world's highly productive sub-tropical continental shelves. Dolioletta gegenbauri blooms often exceed 1,000 zooids $/ \mathrm{m}^{3}$ and extend for hundreds of kilometers (Boero et al., 2008; Deibel \& Lowen, 2011; Frischer et al., 2021; Greer et al., submitted). Salps, a sister group to doliolids also 
form massive blooms but generally in productive ocean environments including the Southern Ocean (Décima et al., in review; Perissinotto \& Pakhomov, 1998; Smetacek et al., 2004; Stukel et al., 2021).

While it is increasingly recognized that blooms of large gelatinous organisms (e.g., jellyfish) influence marine microbial assemblages by releasing large amounts of mucus (Condon et al., 2011; Hao et al., 2019; Lebrato et al., 2019), less is known about the interaction between smaller gelatinous zooplankton species and microbial processes. The link between small gelatinous zooplankton and pelagic microbial communities, however, is potentially more fundamental to ecosystem functioning due to their much higher abundances (Greer et al., 2021; Takahashi et al., 2015; Walters, Lamboley, et al., 2019) and their potential to shunt a considerable fraction of pelagic water column productivity to the microbial food web via the production of microbiallylabile fecal pellets. Doliolids, because they are prolific producers of fecal material (Patonai et al., 2011) may have a particularly large impact on microbial loop processes. Compared to copepods that are highly efficient at digesting prey and produce membrane-bound, dense, and fast sinking fecal pellets (Alldredge \& Madin, 1982; Köster et al., 2011), doliolid pellets contain high quantities of minimally-degraded organic matter, are relatively buoyant, and slow sinking allowing them to linger in surface waters where they can be rapidly colonized by microbial communities (Paffenhöfer \& Köster, 2005; Patonai et al., 2011; Pomeroy \& Deibel, 1980).

As with all pelagic tunicates, doliolids are efficient filter feeders and capable of clearing large volumes of water in both low- and high-food concentration environments (Lucas \& Dawson, 2014). Based on anatomical considerations, laboratory-based experimental studies, and inferences from field observations, doliolids are capable of ingesting particles over a wide size range from less than a micron (bacteria) to 100's of microns (large diatoms, copepod eggs, nauplii) but optimally between 1-50 um (Deibel, 1985; Tebeau \& Madin, 1994). Historically, because of their feeding mechanism, doliolids were assumed to be passive grazers that non-selectively capture particles they encounter (Crocker et al., 1991; Vargas \& Madin, 2004), although some prey items such as diatoms and metazoans are known to be poorly assimilated (Frischer et al., 2021; Paffenhöfer \& Köster, 2005). More recently, however, using molecular gut content analysis and stable isotope tools applied to cultured and wild-caught doliolids, it has been recognized that doliolids are capable of selective feeding and that a significant portion of their diet is likely derived from microbial-processed detrital material (Frischer et al., 2021; Walters, Lamboley, et al., 2019). Recent studies have also suggested that re-ingestion of fecal pellets is an important component of the doliolid diet, especially when phytoplankton abundance is low (Köster \& Paffenhöfer, 2017). Thus, current evidence implies that doliolids may function primarily as detritivores by consuming microbial-enriched particles, acting as a significant driver of shelf microbial processes by feeding on the detrital pool to which they also contribute.

What is the role of the doliolid gut microbiome in fecal pellet processing and acquisition of carbon/nutrients from detrital food sources? Investigations of zooplankton microbiomes are relatively rare, and to date such studies have primarily focused on copepods. Copepod microbiomes contain diverse and abundant bacterial communities (Datta et al., 2018; De Corte et al., 2018; Scavotto et al., 2015; Shoemaker et al., 2019; K. W. Tang et al., 2019) that differ significantly from bacterial communities associated with the surrounding seawater. These studies suggest that crustacean zooplankton-associated bacterial communities are likely shaped by the host species. Similarly, in the few studies that have examined microbiomes associated with gelatinous zooplankton, host microbiomes differed from the surrounding water; however, unlike copepods, the diversity of microbiomes associated with gelatinous zooplankton appears to be very low (Daniels \& Breitbart, 2012; Jaspers et al., 2020; Tinta et al., 2019; Viver et al., 2017). A recent analysis of $>1,000$ specimens across 21 animal phyla further supports the idea that marine invertebrates generally have low-diversity microbiome assemblages that are distinct from surrounding seawater, but many host-associated bacteria may be generalist taxa able to associate with a diversity of host species [and thus marine invertebrates may lack a signature of true phylosymbiosis; (Boscaro et al., 2022)]. In general, the functional significance of marine invertebrate microbiomes is not yet well understood, and host-associated community assembly may be based on functional genes as opposed to species (Burke et al., 2011).

In this study, we expand on previous work elucidating linkages between doliolid feeding ecology and con- 
tinental shelf microbial processes. Here, we specifically focused on characterizing patterns in doliolid gut microbiomes, and microbial communities associated with doliolid fecal-pellets and the surrounding seawater to test the following two hypotheses: 1) doliolids have a low diversity, low biomass microbiome optimized for fecal pellet packaging and acquisition of carbon/nutrition from detrital feeding, and 2) doliolids predictably re-structure particle-associated microbial communities in the continental shelf, impacting both assemblage structure and microbial functional roles. By characterizing microbiomes associated with doliolids that had been feeding in freshly collected seawater containing natural microbial communities and comparing microbiomes associated with the 1) feeding water, 2) fecal pellets, and 3) the animals, interactions between doliolids and microbial communities are inferred. In addition, characterization of starved doliolids provides the first description of the doliolid gut microbiome.

\section{MATERIALS AND METHODS}

\subsection{Collection and culture of doliolids}

Laboratory cultures of D. gegenbauri were initiated and maintained as previously described

(Walters, Gibson, et al., 2019). Briefly, cultures were maintained in filtered ( $~ 0.45 \mu \mathrm{m}$ ) seawater in 3.9L glass jars on a slowly rotating plankton wheel at $20^{\circ} \mathrm{C}$ and supplemented daily with an algal mixture consisting of Isochrysis galbana, Rhodomonas sp. and the diatom Thalassiosira weissflogii. Algal concentrations were maintained at $\sim 80 \mu \mathrm{g} \mathrm{C} \mathrm{L}{ }^{-1}$. Dolioletta gegenbauri zooids were collected using a conical net with a $0.5 \mathrm{~m}$ opening, $202 \mu \mathrm{m}$ mesh net, and a $4 \mathrm{~L}$ aquarium cod end from the mid-shelf region (25-40 $\mathrm{m}$ isobath) of the South Atlantic Bight (SAB) between $29.6-31.2^{\circ} \mathrm{N}$ and $80.1-80.3^{\circ} \mathrm{W}$. The net was towed from a drifting ship by slowly lowering and raising the net through the depth of the water column. The culture was initiated in May 2015 and maintained until the experiments were completed in April 2016. Over the course of this period, the culture was supplemented twice with freshly collected D. gegenbauri zooids in August and December 2015 .

\subsection{Doliolid feeding experiments}

Figure 1 provides an overview of the design of the feeding experiments. Independent feeding experiments were conducted in January 2016 (Exp1), March 2016 (Exp2), and April 2016 (Exp3). Briefly, seawater containing natural microbial communities was collected from the same area in the SAB where doliolids were collected prior to each experiment. Prior to use, water was stored in $20 \mathrm{~L}$ carboys in the dark at $20^{\circ} \mathrm{C}$. Water used in Experiment 1 was collected 1 month prior to the experiment on December 2, 2015, water used in Experiment 2 was collected 2 days prior to the experiment on March 16, 2016, and water used in Experiment 3 was collected 8 days prior to the experiment. Water was collected from near the bottom of the water column where particle concentrations were highest. Over the period that water was collected, near bottom water temperature ranged from 17.0-22.6 $6^{\circ} \mathrm{C}$, salinity ranged from 34.2-35.8 PSU, and chlorophyll $a$ concentration ranged from 1.04-1.14 $\mu \mathrm{g} \mathrm{L}^{-1}$. Experiments were initiated by acclimating $15-20 \mathrm{D}$. gegenbauri zooids from the culture in a 1.9L culture jar containing fresh seawater and allowed to feed for $2 \mathrm{~h}$ while rotating on a plankton wheel. Following the acclimation period, the zooids were transferred to a clean 1.9L jar containing fresh seawater and allowed to feed while on the plankton wheel for an additional $2 \mathrm{~h}$ after which time 5 zooids were sampled. Based on the gut residence times and estimated clearance rates (Gibson \& Paffenhöfer, 2000), it is expected that doliolids would have cleared $250-700 \mathrm{~mL}(13 \%-35 \%)$ of the feeding vessel volume during the $2 \mathrm{~h}$ incubation. Following the feeding period, the remaining zooids were divided into 3 clean 1.9L culture jars and returned to the plankton wheel. Two of the jars contained $10 \mu \mathrm{m}$ filtered water depleted of algal and detrital particles but would be expected to have retained natural bacterial communities. Fecal pellet samples were collected from these jars after $2 \mathrm{~h}$ and $24 \mathrm{~h}$, respectively. To produce starved "Empty Gut" samples to characterize a core gut microbiome, an additional 5 zooids were incubated for $24 \mathrm{~h}$ in a third 1.9L jar containing $0.2 \mu \mathrm{m}$ filtered seawater. An initial series of 3 pilot experiments conducted in 2012 and following the procedures described above generated the materials used to estimate bacterial concentrations 
in starved (EG), aged fecal pellets (FP24h), and seawater (SW) by quantitative PCR (qPCR).

Over the course of each experiment four types of samples were collected for $16 \mathrm{~S}$ metabarcoding characterization (Fig. 1). Seawater (SW) containing natural microbial communities was sampled at the start of the $2 \mathrm{~h}$ feeding period of experiment. Prior to filtration, the water was pre-filtered through a $63 \mu \mathrm{m}$ sieve to remove any larger aggregates and metazoans. Triplicate $500 \mathrm{~mL}$ samples were gently filtered onto $25 \mathrm{~mm}$ $0.2 \mu \mathrm{m}$ Supor filters (PALL Life Sciences, East Hills, NY, USA). Filters were placed in sterile $2 \mathrm{~mL}$ cryovials and stored at $-80^{\circ} \mathrm{C}$ until DNA was extracted. Following the $2 \mathrm{~h}$ feeding period, 5 zooids with full guts (FG) were sampled to characterize microbial communities associated with both the doliolid and the prey that was consumed. These samples were expected to be dominated by fresh fecal material. Following $2 \mathrm{~h}$ of incubation in $10 \mu \mathrm{m}$ filtered seawater fecal pellets were collected (FP2h). This material was considered freshly released and representative of initial colonization by natural bacterial communities. Following $24 \mathrm{~h}$ of incubation in $10 \mu \mathrm{m}$ filtered seawater a second set of fecal pellet samples were collected (FP24h). This material was considered aged fecal material and representative of material with a developed mature microbial community. It was not possible to recover intact pellets after $24 \mathrm{~h}$ as they were highly degraded and had either broken-up completely or dissolved.

Following collection of D. gegenbauri zooid samples, zooids were stabilized prior to DNA extraction as previously described (Walters, Lamboley, et al., 2019). Briefly, zooids were anesthetized in $0.2 \mu \mathrm{m}$ filtered seawater containing 0.4\% MS-222 (3-aminobenzoic acid ethyl ester; Alfa Aesar). After rinsing each zooid three times in fresh $0.2 \mu \mathrm{m}$ filtered seawater containing MS-222 they were transferred to $2 \mathrm{ml}$ tubes containing extraction ATL buffer from the DNeasy Blood and Tissue kit (Qiagen, Valencia CA, USA). Fecal pellets were collected by centrifugation $(500 \mathrm{x} \mathrm{g}$ for $5 \mathrm{~min}$ ) after they were rinsed 3 times in $0.2 \mu \mathrm{m}$ filtered seawater. Pellets were transferred to $2 \mathrm{~mL}$ tubes containing extraction ATL buffer. All samples were stored at $4^{\circ} \mathrm{C}$ until DNA was extracted, usually within $24-48 \mathrm{~h}$ after initial collection.

\subsection{DNA extraction, PCR, and Illumina sequencing}

Genomic DNA from doliolid zooids was extracted and purified using the Qiagen DNeasy Blood \& Tissue kit. DNA from water samples was purified using the Qiagen PowerWater kit (Qiagen, Valencia CA, USA). Manufacturer instructions were followed for both kits. Purified DNA extracts were quantified using a Qubit (B) 2.0 Fluorometer with the dsDNA HS assay reagents (ThermoFisher Scientific). Yields ranged from 40-254 ng $(0.20-1.3 \mathrm{ng} / \mu \mathrm{L})$ DNA per gonozooid and $0.26-0.49 \mathrm{ng} / \mu \mathrm{L}$ DNA per $100 \mathrm{~mL}$ of water. DNA samples were stored at $-20^{\circ} \mathrm{C}$ until further analysis.

DNA extracts were used to amplify (in triplicate) the V4 region of the 16S rRNA gene using the primers 515F (Parada et al., 2016) and 806R (Apprill et al., 2015). Dual-index primer constructs were designed by modifying the Earth Microbiome Project (EMP) Illumina amplicon protocol as described in Schuelke et al. (2018). All primer constructs and oligo sequences have been made available on FigShare (https: //doi.org/10.6084/m9.figshare.5701090). Amplification of the 16S rRNA gene was performed following the EMP protocols (Caporaso et al., 2012). PCR reactions contained $1 \mu \mathrm{L}$ of DNA template, $0.5 \mu \mathrm{L}$ of each primer $(10 \mu \mathrm{M}), 10 \mu \mathrm{L}$ of Platinum Hot Start PCR Master Mix (2x) (Thermo Fisher), and $13 \mu \mathrm{L}$ of molecular-grade water. Positive (ZymoBIOMICS ${ }^{\mathrm{TM}}$ Microbial Community Standard; Zymo Research, Irvine, CA) and negative (molecular-grade water, HyClone HyPure Water, GE, Healthcare Life Sciences) controls were included in all PCRs. Thermocycling profile included the following steps: $94^{\circ} \mathrm{C}$ for $3 \mathrm{~min}$; $94^{\circ} \mathrm{C}$ for $45 \mathrm{~s}, 50^{\circ} \mathrm{C}$ for $60 \mathrm{~s}$ and $72^{\circ} \mathrm{C}$ for $90 \mathrm{~s}$ for 35 cycles; and $72^{\circ} \mathrm{C}$ for $10 \mathrm{~min}$. Amplification success was evaluated with gel electrophoresis (agar 1\%). Additional details on PCR conditions and purification are also provided in Schuelke et al. (2018).

Sample DNA concentrations were measured using a Qubit@ 3.0 Fluorometer with the dsDNA HS (High sensitivity) Assay Kit (Thermo Fisher Scientific) and normalized prior to pooling. The DNA library was subjected to a final magnetic bead cleanup step, followed by size selection (300-700 bp range) on a BluePippin (Sage Science, Beverly, MA) to remove any non-targeted DNA. A Bioanalyzer trace was run on the size- 
selected pool as a quality control measure, and the library sequenced on the Illumina MiSeq Platform $(2 \mathrm{x}$ 300-bp paired-end run) at the UC Davis Genomics Core Facility (Schuelke et al., 2018). All wet laboratory protocols and downstream bioinformatics scripts used in this study have been deposited on GitHub (https: //github.com/BikLab/doliolids).

\subsection{Quantitative polymerase chain reaction (qPCR) assay}

Bacterial abundances associated with EG, FP24h, and SW sample types were estimated by real-time qPCR on a Bio-Rad CFX96 Real-Time PCR System (Bio-Rad Laboratories, Hercules, California) using 932F and 1062R universal 16S rRNA targeted primers (Allen et al., 2005). qPCR reactions were performed in 20

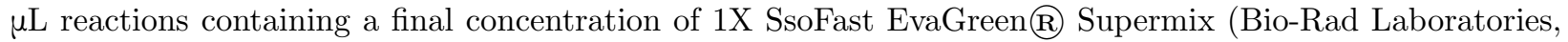
Hercules, California), $0.3 \mu \mathrm{mol}$ of each primer, and $1 \mu \mathrm{L}$ genomic DNA per reaction. Quantitative standard curves were generated from a 6-order of magnitude serial dilution of plasmid DNA (pDNA) containing a cloned copy of the target $16 \mathrm{~S}$ rRNA gene $\left(E\right.$. coli) ranging from $10^{1}$ to $10^{7}$ target gene copies per reaction. qPCR cycling conditions included the following steps: $95{ }^{\circ} \mathrm{C}$ for $30 \mathrm{~s}$ followed by 45 cycles of denaturation $\left(95{ }^{\circ} \mathrm{C}, 5 \mathrm{~s}\right)$ and annealing/extension $\left(54.7^{\circ} \mathrm{C}, 5 \mathrm{~s}\right)$. After cycling, product melt temperatures were evaluated from 60 to $95{ }^{\circ} \mathrm{C}$ at $0.5{ }^{\circ} \mathrm{C}$ increments for $5 \mathrm{~s}$ each. Samples, standards, and no-template controls were assayed in triplicate. rRNA gene copy numbers were normalized to volume. Volumes of doliolids and fecal pellets were estimated from microscopically determined size estimates assuming a barrel and spherical shape, respectively.

\subsection{Bioinformatics and statistical analyses}

Raw Illumina data were demultiplexed using a custom script for handling dual-index barcodes and then analyzed in QIIME2 version 2020.11 (Bolyen et al., 2019). Primer and adapter sequences were trimmed (error rate of 0.1 and reads discarded when lacking adapter/primer) using the cutadapt plugin (Martin, 2011). Denoising was based on optimal parameters (forward and reverse reads truncated at 237 and 253 bp, respectively; median PHRED score of [?]30). Amplicon Sequence Variants (ASVs) were estimated using the high-resolution single-nucleotide difference DADA2 method (Callahan et al., 2016) based on default parameters and consensus chimera checking parameters. Taxonomy assignments of ASVs were obtained with the BLAST+ consensus taxonomy classifier [minimum confidence value of 0.8; (Camacho et al., 2009)] and the SILVA 138 SSURef NR99 release (Quast et al., 2013).

Our final dataset consisted of 115 samples, and except for PCR negative controls, all had high sequence depth ( $>2,000$ reads, Table S1, Appendix S1). Preliminary analyses revealed that ASVs found in PCR controls were not shared by experimental samples (Fig. S1, Appendix S2). Still, the R package decontam (prevalence; threshold of 0.5) was used to assess the levels of contamination in the dataset (Davis et al., 2018). Only four ASVs were identified as contaminants, which were removed prior to analyses assessing patterns of microbial community variation among sample types.

Diversity estimates including Observed, Shannon H' $\left(\log _{2}\right)$, Inverted Simpson (D), and Pielou's Evenness (J') were extracted from the filtered ASV table using the package phyloseq (McMurdie \& Holmes, 2013), and compared among sample types for each experiment separately. Data normality was assessed using ShapiroWilk's method, and Kruskal-Wallis $(\mathrm{K}-\mathrm{W})$ tests were used to assess differences among sample types with the package FSA v0.8.24 in R version 4.1.2 (R Core Team, 2021). The Mann-Whitney U test with adjustments for p-value [BH method; (Benjamini \& Hochberg, 1995)] was used for pairwise comparisons (Zar, 2010).

To visualize the similarity of microbial communities among sample types, a similarity matrix based on BrayCurtis similarity and ASV-transformed abundances standardized by total and square root transformed values was constructed. Ordination was done by Non-parametric Multidimensional Scaling (nMDS) and Goodnessof-fit given by the stress value (Clarke, 1993). The Permutational Analysis of Variance (PERMANOVA) was used to test for significance among sample types (Anderson et al., 2008). 
Differential abundance analyses were performed using the $\mathrm{R}$ package $A L D E x 2$ (v1.12.0) (Fernandes et al., 2013, 2014). ASV counts were transformed using the Centered-Log Ratio method for a compositionally coherent inference and estimates. Significant differences $(p<0.05)$ among sample types were assessed through $\mathrm{K}-\mathrm{W}$ tests at each taxonomic rank. False discovery rates (FDRs) were estimated using the BenjaminiHochberg procedure (Benjamini \& Hochberg, 1995). A heatmap (taxa: rows; samples: columns) depicting the variation among sample types of taxa differentially abundant was produced. PICRUSt2 was used to predict potential gene functions from microbial community profiles associated with sample types (Douglas et al., 2020). Differential abundance analyses on the matrices of predicted gene functions were performed and visualized as described above. Additionally, predicted gene functions were organized into distinct metabolic pathways following Yilmaz et al. (2015). In this study, all visualizations were produced with ggplot2 v.3.1.1 (Wickham, 2016) using R v.4.1.2 (R Core Team, 2021).

\section{Results}

\subsection{Estimates of bacterial abundance}

Bacterial biomass, as inferred from 16S rRNA gene copy abundance, was assessed by qPCR and normalized to sample volume (Fig. 2). Bacterial cell numbers were not estimated from rRNA copy numbers because rRNA copy number is known to vary based on cell type and activity (Klappenbach et al., 2001). The abundance of bacterial rRNA gene copies in FP24h was at least two orders of magnitude higher than that found in SW $\left(8.0+-7.1 \times 10^{5}\right.$ vs. $1.3+-1.8 \times 10^{3}$ copies $\left.\mathrm{mm}^{-3}\right)$ indicating that fecal pellets support the rapid proliferation of bacterial communities. In contrast, the abundance of $16 \mathrm{~S}$ rRNA copies was an order of magnitude lower in EG samples compared to the water column on a per-volume basis $\left(0.05+-0.01 \times 10^{3}\right.$ copies $\left.\mathrm{mm}^{-3}\right)$.

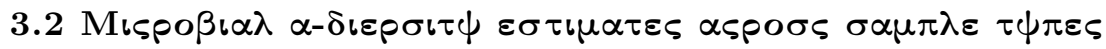

Overall, the mean number of reads and ASVs were similar across experiments (Exp1: 32,274 and 139, Exp2: 38,518 and 144, Exp1: 27,833 and 145; Fig. 3). Lowest diversity estimates were observed in EG samples, except in Experiment 1 where the lowest diversity observed was in the FG samples. Conversely, $\alpha$-diversity estimates were generally highest in SW samples followed by either FP2h or FP24h. A summary of comparisons across sample types for the number of reads and different diversity estimates is provided in Figure 3.

Significant differences $(p<0.05, \mathrm{~K}-\mathrm{W}$ analysis) among sample types were detected for all the diversity indices. Pairwise comparisons revealed that EG samples often had significantly lower values for all $\alpha$-diversity indices when compared to the other sample types. Alternatively, equivalent $\alpha$-diversity levels were observed $(p>0.05)$ in the SW, FP2h, and FP24h samples (Fig. 3; Table S2, Appendix S1).

Only $20-30 \%$ of ASVs (30-40) were shared among all sample types. In Experiments 1 and 3, the highest number of shared ASVs was observed between FG and FP2h/FP24h samples $(26$ and 79 ASVs, respectively), whereas in experiment 2, the highest number (55 ASVs) was observed between FG and FP24h samples (Fig. S2, Appendix S2). The FG samples contained the most unique ASVs (221-566), especially in Experiments 2 and 3, whereas FP2h and FP24h often had the lowest number of ASVs (Fig. S2, Appendix S2).

At the phylum level, microbial communities associated with the different sample types were dominated by four (out of 37 phyla) major groups including Proteobacteria (up to 95\%), Cyanobacteria (up to 59\%), Planctomycetota (up to 38\%), and Bacteroidota (up to 16\%; Fig. 4A; Fig. S3, Appendix S2). Whereas Proteobacteria was highly abundant in all experiments and sample types, especially in the SW and EG samples, Cyanobacteria and Planctomycetota tended to be more abundant in FG and fecal pellets samples (Fig. 4A). Interestingly, of the Proteobacteria, the EG and aged FP (FP24h) samples were generally dominated by representatives of the Enterobacterales while the other sample types were dominated by Pseudomonadales or Rhodobacterales (Fig. 4B). The presence of SAR11 (Alphaproteobacteria) was primarily observed in SW 
samples (9-38\%). Of these, representatives of SAR11 Clade 1a were most common. Moreover, SW samples were often characterized by many low abundant taxa classified as "Others" (Fig. 4; Fig. S5, Appendix S2).

\subsection{Potential evidence for a core microbiome in the doliolid gut}

To explore the presence of a "core microbiome" in the doliolid gut, we analyzed EG samples in greater detail. A total of 29 ASVs were exclusively found in EG samples with nine often recovered as [?]50\% in all three feeding experiments (Fig. 5). These ASVs may be representative of a doliolid core microbiome. Among these potential core taxa, the genera Pseudoalteromomas and Shimia were the most abundant. Other potential core microbiome members include the genera Pelagibaca and Alteromonas. In addition to being abundant in the EG samples, these taxa were recovered in all EG samples (Table S4, Appendix S1). Although EG doliolids harbored a considerable number of unique ASVs (148-250), less than 50 of these were shared with other sample types (Fig. S2, Appendix 2). Together, these findings support the idea that EG doliolids have a distinct microbial community.

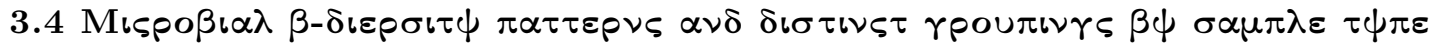

Regardless of the experiment, microbial communities were always structured by sample type (Fig. 6). The least diverse EG samples clearly separated from the other sample types. Although significantly different, FG, FP2h, and FP24h tended to be close in nMDS bi-dimensional space, whereas SW samples also differed from all other sample types (Fig. 6).

PERMANOVA analysis confirmed that the associated microbial community significantly differed among sample types. Highest similarity values were always found between FP2h and FP24h sample types (52.7-54.8\%) and lowest between SW and FG (10.2\%) or between SW and EG (2.9-9.1\%) sample types. In other words, fecal pellet microbial communities tend to always resemble each other, whereas the doliolid gut microbiome exhibits a unique and distinct microbial community structure compared to seawater. The analysis of average similarity also indicated that the microbial communities associated with FG and SW samples were more similar to those in the FP2h or FP24h samples. These values, however, were often higher between FG and fecal pellets than between SW and fecal pellets (Table S5, Appendix S1).

\subsection{Differential abundance analysis of microbial taxa}

Among bacterial phyla, Planctomycetota was the most differentially abundant taxa across sample types in all three experiments and it was consistently more abundant in FP2h, FP24h, and FG samples. The SAR324 MG-B group was important in SW samples in all three experiments (ranked in 5, 10, and 12 in abundance, respectively), in addition to Marinimicrobia (ranked 15 and 16 in abundance) and Bacteroidota (ranked 8 and 6 in abundance, respectively). Conversely, Acidobacteriota was differentially and more commonly found in EG and FG samples. Cyanobacteria was differentially abundant in all three experiments (ranked 4, 2, and 2 in abundance, respectively) and particularly important in the FP2h, FP24h, and FG samples (Fig. $7)$.

At the genus level, sample types including FP2h, FP24h, and to a lesser extent FG, displayed similar patterns of differentially abundant taxa (Fig. S4, Appendix 2). For example, an uncharacterized Pirellulaceae family member was most important in these three sample types. In the EG sample Alteromonas was differentially abundant whereas Cyanobium PCC-6307 and Blastopirellula were relatively important across all sample types, except in EG doliolids. Variation of differentially abundant taxa across sample types and experiments was also observed (Appendix S1, Table S6).

\subsection{Predicted functional genes and metabolic pathways}


The most abundant predicted metabolic functions were consistently recovered across sample types and experiments and reflected the core functions of microbial cellular machinery. For example, a DNA polymerase (EC:2.7.7.7), was recovered with higher predicted abundance (always $>1 \%$ ) in SW, EG, and FG samples and a DNA helicase (EC:3.6.4.12) in FP2h. Uronate dehydrogenase (EC:1.1.1.203) was also important in all sample types, except EG doliolids, whereas Tryptophan 2,3-dioxygenase (EC:1.13.11.11) was more important in EG and SW samples. Differentially abundant predicted functions also supported similarities among FP2h, FP24h, FG, and to a lesser extent SW sample types (EC:2.7.1.31 - Glycerate 3-kinase, EC:2.3.1.31 Homoserine O-acetyltransferase). A summary of the most differentially abundant predicted gene functions for each experiment is provided in Figure S6 (see Table S7, Appendix S1 for additional details).

Similar to the separation observed in the nMDS analysis of the composition of doliolid associated microbial communities (Fig. 6) sample types were also separated by predicted functional genes (Fig. S7, Appendix 2). The predicted functions/genes recovered in the PICRUSt2 analysis, and differently abundant among sample types, were also grouped into key metabolic processes in the marine environment including nitrogen, carbon, and sulfur cycling (Fig. 8). The contribution of individual predicted functions/genes to the overall abundance was often low $(\mathrm{RA}<0.1 \%)$ and varied according to the feeding experiment. Nevertheless, key genes including those involved in the nitrogen (Ammonification: ure $C$, Denitrification: $\operatorname{nar} G, \mathrm{~N}$ reduction: $\operatorname{nas} A$ and $\operatorname{nir} B$ ) and sulfur (Sulfate reduction: sat, met3) cycling were predicted to contribute to the functional potential found in the different sample types. The major contributor to a specific predicted function also varied by experiment. For example, the major contribution to $\operatorname{nar} G$ (EC:1.7.99.4) involved in denitrification came from SW, FG, and EG for experiments 1, 2, and 3, respectively. A complete list of the predicted functions/genes and their contribution to specific metabolic processes are provided in Appendix S1 (Table S8).

\section{DISCUSSION}

Gelatinous filter-feeding zooplankton including doliolids, because of their intimate relationship with microbial-rich particles are likely critical mediators between the grazing food web and microbial mediated biogeochemical cycling (Frischer et al., 2021). Despite the likely importance of doliolids as a conduit of energy and matter into the microbial loop rather than into the grazing food web, the relationship between microbial loop processes and doliolids has not been carefully investigated. In this study we focused on characterizing doliolid-associated microbiomes and ecosystem components (seawater and fecal pellets) that they directly interact with. Characterization of doliolid microbial communities using a 16S rRNA targeted metabarcoding approach indicates that at the highest taxonomic levels, doliolid-associated bacterial communities are characteristic of marine bacterioplankton communities around the globe (Coutinho et al., 2021; Schauer et al., 2003; Silva et al., 2017; Yilmaz et al., 2015). Doliolid associated bacterial communities were

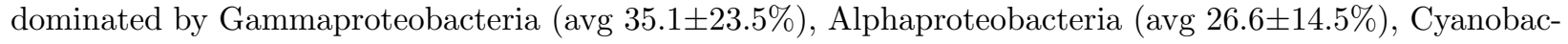

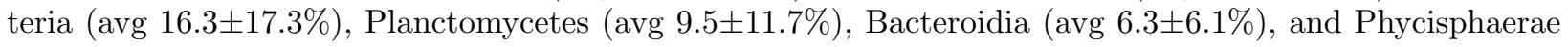

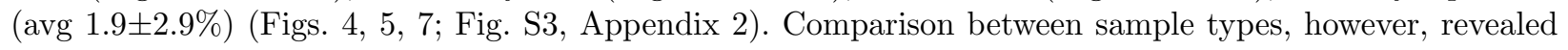
distinct patterns in diversity and biomass.

\subsection{Doliolids have a low-diversity microbiome distinct from surrounding seawater and fecal pellets}

Bacterial communities associated with starved doliolids (EG), presumably representative of the doliolid gut microbiome, possessed the lowest volume normalized biomass (log $1.7 \pm 0.1 \mathrm{~mm}^{-3}$; Fig. 2) and lowest $\alpha$-diversity ( $\mathrm{H}^{\prime}=2.24 \pm 0.75$; Fig. 3 ) of all the sample types examined in this study. In the three independent experiments conducted, the number of ASVs that were unique to EG samples averaged $13.5 \pm 2.2 \%$ of the total ASVs observed among all the samples and support the hypothesis that doliolids possess a unique but low diversity, low biomass microbiome, similar to previous descriptions of the microbiomes of marine gelatinous species (Berger et al., 2021; Daley et al., 2016; Daniels \& Breitbart, 2012; Kos Kramar et al., 2019; Thompson et al., 2021). This observation is consistent with the hypothesis that the doliolid gut is a 
highly specialized environment optimized for detritivory and the emerging understanding that trophically doliolids are functional detritivores (Frischer et al., 2021). Among the potential core taxa, representatives of the Gammaproteobacteria class in the genus Pseudoalteromomas and the Alphaproteobacteria class in the genus Shimia were the most abundant taxa recovered. Both these groups of bacteria are typically associated with the digestion of marine autotrophic biomass in marine invertebrates, including gelatinous species (Choi \& Cho, 2006; Thomé \& Rivera-Ortega, 2022). Interestingly, marine Pseudoalteromomas species are often reported to be associated with marine eukaryotes [especially microbial metazoan taxa; (Boscaro et al., 2022)] and are known to exhibit a range of anti-bacterial, bacteriolytic, agarolytic and algicidal activities (Bosi et al., 2017; Holmström \& Kjelleberg, 1999). Their presence in the doliolid microbiome may help explain the low bacterial biomass and diversity observed in the EG doliolids.

In contrast to the doliolid gut microbiome, microbial communities in seawater in which the doliolids had been contained exhibited the highest $\alpha$-diversity ( $\mathrm{H}^{\prime}=3.84 \pm 0.4$; Fig. 3 ) and intermediate biomass $(\log 2.72 \pm 0.7$ $\mathrm{mm}^{-3}$; Fig. 2). Seawater bacterial communities were characterized by relatively high proportions of wellknown oligotrophic members of the SAR11 clade, particularly representatives of SAR11 clade 1a. This group of bacteria are typical oligotrophic members of ocean bacterioplankton including in the SAB (Giovannoni, 2017; Lu et al., 2015). Seawater microbial assemblages were also characterized by a large number of low abundance bacterial taxa in addition to bacterial taxa that were common in all doliolid sample types.

Bacterial communities associated with full gut animals and fecal pellets exhibited intermediate $\alpha$-diversity $\left(\mathrm{H}^{\prime}\right.$ $=3.27-3.58)$ and high biomass ( $\log$ rRNA copies $=2.5-5.7)$. These observations are consistent with selection for copiotrophic microbial communities in fecal material capable of utilizing nutrient rich prey particles concentrated by the doliolid feeding (Gasol \& Kirchman, 2018). The similarity of microbial communities associated with full gut animals that are presumably largely derived from imported microbes because biomass of empty gut animals is so low, suggest that digestion of prey particles is initiated in the concentrated environment of the doliolid gut but completed following egestion where additional microbial communities are recruited from bacterial communities present in the surrounding seawater.

Micro-eukaryotic components of fecal pellet and doliolid gut communities were not explored in this study but are likely to also be present and contribute to the processing of consumed and egested materials. Pomeroy and Deibel (1980) reported observing that fresh D. gegenbauri pellets contained dense bacterial populations followed by protistan communities that persisted for up to 4 days by consuming bacteria. Previous studies investigating the diet of $D$. gegenbauri in the SAB that utilized 18S rRNA targeted Molecular Gut Content Analysis approaches reported that wild caught D. gegenbauri gut samples contained diverse protist communities (Frischer et al., 2021; Walters, Lamboley, et al., 2019). It could not be determined in these studies whether these organisms were consumed as prey or recruited as symbionts.

Although there was considerable variability between experiments in terms of the overall composition of microbial communities (Fig. 3), the observed microbial assemblages were consistently structured by sample type across experiments (Fig. 6). In all three experiments, bacterial communities associated with each sample type were more similar to themselves than bacterial assemblages recovered from other sample groups. Empty gut samples clustered together separated from full gut and fecal pellet-associated communities, and seawater-associated communities. Despite differences in bacterial communities present in the seawater, the relationships in similarity between communities associated with the different sample types remained consistent supporting the hypothesis that the presence of doliolids and the environments and particles that they produce predictably influence the structure of microbial communities.

\subsection{Ecological significance of doliolid microbial interactions: implications for biogeochemical cycling in marine pelagic ecosystems}

Comparisons between bacterial communities associated with seawater, feeding doliolids, and fecal materials derived from these experimental studies suggests that through their presence and trophic activity, doliolids influence the structure of pelagic food webs and biogeochemical cycling in subtropical continental shelf 
systems where doliolid blooms are common. The presence of both copiotrophic bacteria and typical oceanic oligotrophic bacteria in seawater samples suggests that the activities of doliolids enrich oceanic microbial communities with copiotrophic bacteria supporting the hypothesis that doliolid blooms, similar to jellyfish blooms, would be expected to intensify system heterotrophy, reduce the efficiency of the biological pump, and limit trophic transfer to the grazing food web (Condon et al., 2011; Tinta et al., 2021).

The presence of doliolids may also influence biogeochemical cycling. In this study, the functional potential of microbial communities associated with the different doliolid sample types was predicted, providing initial insights into how doliolids and their fecal pellets may impact the ocean microbial loop and metabolic processes. Although functional predictions based on 16S rRNA sequencing have significant limitations (Sun et al., 2020), with growing databases and experimental validation, the reliability of this approach has been rapidly improving (Douglas et al., 2020). Importantly, these predictions provide a basis for generating hypotheses related to the functional potential of microbial communities associated with doliolids and their fecal pellets that will be useful for guiding future research utilizing more specific approaches including transcriptomic studies (Suárez-Moo et al., 2020; Voogd et al., 2015; Yilmaz et al., 2015).

The predicted functional analysis conducted in this study identified a large number of genes related to ecologically significant metabolic processes. Those that were detected at high relative abundances $(<0.1)$ and were related to ecologically significant biogeochemical cycling processes are discussed here. Key genes involved in the nitrogen cycle (Kuypers et al., 2018) and sulfur cycle (K. Tang, 2020) were detected as being over-represented in doliolid associated samples. For example, genes involved in nitrogen reduction $($ nir B) and denitrification (nirS, nir K, and nos Z) were predicted to be present in fecal pellets (especially FP2h) in all three experiments. Nitrogen fixation $(n i f \mathrm{H})$ was predicted to be associated with EG doliolids and fecal pellets suggesting that doliolids may enhance the $\mathrm{N}$ content of ingested detrital particles. Interestingly, Scavotto et al. (2015) reported nifH in seawater particles and full gut copepods leading the authors to conclude that copepods may acquire the bacteria capable of $\mathrm{N}_{2}$ fixation through feeding. The proportion of potential bacteria carrying nifH in SW samples, however, was low in this study suggesting that doliolids may acquire nifH differently than copepods. The presence of genes involved in sulfur cycling including $d m d \mathrm{~A}$ involved in the metabolism of dimethylsulfoniopropionate was also predicted to be elevated in abundance in EG doliolid, fecal pellets and seawater suggesting the involvement of doliolids in key sulfur cycling processes. In ctenophores, Daniels and Breitbart (2012) associated this potential functional with high abundance of the bacterial genus Marinomonas. Various members of the Marinobacter group including Marinomonas were identified in this study as a potential member of the doliolid core microbiome (Fig. 5).

Predicted functions to degrade organic compounds including chitin were relatively abundant in doliolid materials compared to seawater samples. Chitinase (EC:3.2.1.14) encoding genes, for example, were detected at high relative abundances in FP24h and EG samples (Fig. S6, Appendix 2). Similarly, De Corte et al. (2018), using a metagenomic approach, speculated on the potential of zooplankton-associated bacterial communities in metabolizing chitin and other complex organic molecules based on the presence of chitinase encoding genes. Chitin degradation in copepods (Scavotto et al., 2015) and jellyfish (Kos Kramar et al., 2019) have been associated with bacterial communities dominated by Vibrio spp. In this study, the proportion of Vibrionaceae including Vibrio, although relatively low and mostly restricted to Experiment 3, was primarily found in FG and EG samples. Chitinases have also been reported to be produced by Pseudoalteromomas ssp. (Cottrell et al., 2000), a taxon extremely abundant in EG samples of Experiment 2. In fact, predicted abundances of potential bacteria that may produce chitinases were highest in EG samples from Experiment 2.

\section{CONCLUSIONS}

To our knowledge, this is the first study to characterize the bacterial communities associated with doliolids and their fecal pellets using a 16S rRNA metabarcoding approach. Our results suggest that doliolid-associated microbial communities play important roles in the biology and ecology of doliolids and influence pelagic marine bacterioplankton communities and the processes they mediate. Because doliolids are capable of forming massive blooms in some of the most productive regions of the ocean, the ecological implications of 
doliolid microbe interactions are likely to be significant. While many physical, chemical, and biological factors influence the composition and stability of host-associated microbiomes, our analysis of starved doliolids suggest that some microbial taxa are likely part of a resident low-biomass doliolid microbiome. 16S rRNA metabarcoding distinguished bacterial communities associated with the different sample types providing new insights into the interactions between doliolids and microbial communities in productive sub-tropical continental shelf systems. Comparison of microbial communities found in seawater to doliolid associated communities support the hypothesis that doliolid blooms would be expected to intensify system heterotrophy, reduce the efficiency of the biological pump, and limit trophic transfer to the grazing food web. Exploratory

bioinformatic analyses of predicted functional genes suggest that doliolids, via their interactions with bacterial communities, may affect important biogeochemical processes including nitrogen, sulfur, and organic matter cycling.

\section{AUTHOR CONTRIBUTIONS}

T.J.P., T.L.W., H.M.B., and M.E.F. designed and conceived the study, contributed to data analysis, and wrote the manuscript. T.J.P. completed 16S rRNA PCR amplification, prepared libraries for Illumina sequencing, processed raw sequence data analysis, and executed bioinformatics workflows. T.L.W. performed feeding experiments and performed DNA extractions from all sample types. H.M. E. conducted qPCR analysis and provided intellectual contributions to the manuscript. All authors read and approved the final version of the manuscript.

\section{ACKNOWLEDGEMENTS}

This study was supported in part by the U.S. National Science Foundation collaborative awards OCE 1459293 and OCE 2023133 (M.E.F) and institutional startup funding from the University of Georgia (H.M.B). We would like to thank the hardworking and professional crew of the R/V Savannah for facilitating collection of doliolids and seawater samples that were used in this study. We also thank the editor and two anonymous reviewers for the many constructive comments on a previous version of the manuscript.

\section{DATA AVAILABILITY STATEMENT}

Raw Illumina reads generated in this study have been submitted to the NCBI Sequence Read Archive (BioProject PRJNA863883 and SRA accession SUB11852035). Primer constructs, QIIME mapping files, and final ASV tables have been deposited in FigShare (https://doi.org/10.6084/m9.figshare.5701090). All scripts used for processing and analyzing the data are available on GitHub (https://github.com/BikLab/ doliolids).

\section{Figure Legends}

Figure 1. Schematic of experimental design used to produce the samples analyzed in this study. Experimental procedures (clear boxes) and samples collected (dark boxes) are highlighted. Inset: A) micrograph of Dolioletta gegenbauri gonozooid, B) Culture jar (1.9L) used to acclimate and feed doliolids, C) Plankton wheel used to incubate doliolids and produce fecal pellet samples.

Figure 2. Abundance (mean $\pm \mathrm{SE}$ ) of bacterial communities associated with EG, FP24h, and SW samples. Bacterial abundance was inferred from 16S rRNA gene copy abundance quantified by quantitative PCR (qPCR) and normalized to sample volume. For significant differences $(p<0.05)$ in pairwise comparisons among sample types, the reader is referred to Table $\mathrm{S} 2$.

Figure 3. Univariate descriptors (mean $\pm \mathrm{SE}$ ) for microbial communities associated with doliolids (FG and EG), fecal pellets (FP2h and FP24h), and seawater (SW) samples in different feeding experiments (1-3). 
Observed diversity refers to the number of unique ASVs. Only significant differences $(p<0.05)$ among sample types are shown (see Table S3 for additional details).

Figure 4. Microbial community composition associated with doliolids (FG and EG), fecal pellets (FP2h and FP24h), and seawater (SW) samples in different feeding experiments (1-3). Taxonomy of the 11 most abundant bacterial phyla (A) and orders (B) are given. Low abundance taxa were grouped into the "Others" category. Relative abundance of taxa contributing to [?]5\% is displayed in the barplots.

Figure 5. Abundance (mean +-SE) of nine frequently recovered bacterial taxa (abundance [?] 50\%) in EG samples across different feeding experiments. Additional information, including from other taxa often recovered in EG samples, is provided in Table S4.

Figure 6. Microbial community structure according to experiment (A: experiment 1, B: experiment 2, C: experiment 3) and sample types: doliolids (FG and EG), fecal pellets (FP2h and FP24h), and seawater (SW). The nMDS ordination is based on the Bray-Curtis similarity constructed from the relative abundance of ASVs (square root transformed). Control samples and ASVs determined to be contaminants were removed from the analysis (see Methods for additional details; Fig. S1, Appendix 2).

Figure 7. Heatmap of the most differentially abundant microbial taxa (phylum level) across sample types (EG: empty gut, FG: full gut, FP24h: fecal pellet 24h, FP2h: fecal pellet $2 \mathrm{~h}, \mathrm{SW}$ : seawater) and experiments. Taxon abundance was transformed using the centered-log ratio (CLR). For each taxon, warm colors indicate high abundance whereas cold colors indicate low abundance. A complete list of taxa differentially abundant for each taxonomic rank across sample types is provided in Table S6.

Figure 8. Heatmap of differentially abundant predicted functions associated with carbon, nitrogen, and sulfur cycling across sample types (EG: empty gut, FG: full gut, FP24h: fecal pellet 24h, FP2h: fecal pellet $2 \mathrm{~h}, \mathrm{SW}$ : seawater) and experiments. The abundance of different functions/genes was transformed using the centered-log ratio (CLR). Warm colors indicate high abundance whereas cold colors indicate low abundance. A complete list of functions/genes differentially abundant, including their description, for each experiment and across sample types is provided in Table S7.

\section{Supporting/Supplemental Information}

\section{Appendix S1}

Table S1. Sequencing depth, including descriptive metrics across sample types and experiments. Data include the number of reads fed to and retained (non-chimeric) by DADA2 as well as the number of unique ASVs. The final read and ASV counts from each experimental dataset were used for statistical and ecological analyses.

Table S2. Pairwise comparisons for the bacterial abundance across sample types. Bold values indicate significant differences $(p<0.05)$.

Table S3. Pairwise comparisons for the number of reads and $\alpha$-diversity indices across sample types in each experiment. $\mathrm{K}-\mathrm{W}$ analysis was used to test for significant differences among sample types. Bold values indicate significant differences $(p<0.05)$ after correction for FD using the BH method. In each experiment, the lowest (light orange) and highest (light blue) values for each metric are highlighted.

Table S4. Bacterial taxa shared by 29 EG samples from all three feeding experiments. Highly frequent taxa (abundance [?] 50\%) are highlighted in gray. For each bacterial taxon, mean abundance values (including Min-Max) and frequency are provided.

Table S5. Summary results from PERMANOVA analysis including pairwise comparisons among sample types for each experiment. Average similarity within (diagonal values in bold) and among sample types are also provided. Abbreviations: df: degrees of freedom; SS: sum of squares; MS: mean square; Pseudo-F: F 
statistic; $\mathrm{P}(\mathrm{MC})$ : p-value obtained with Monte Carlo permutation test; Res: residual. Bold values indicate significant differences $(p<0.05)$.

Table S6. Results from differential abundant analysis with ALDEx2 for microbial taxa (phylum-genus level) across sample types (EG: empty gut, FG: full gut, FP24h: fecal pellet 24h, FP2h: fecal pellet $2 \mathrm{~h}$, SW: seawater) and experiments (Experiment 1, Experiment 2, Experiment 3). Taxon total abundance (and relative abundance RA\%) is given for each sample type.

Table S7. Results from differential abundance analysis with ALDEx2 for predicted functional functions across sample types (EG: empty gut, FG: full gut, FP24h: fecal pellet 24h, FP2h: fecal pellet 2h, SW: seawater) and experiments (Experiment 1, Experiment 2, Experiment 3). Mean abundance of predicted functions across sample types is provided.

Table S8. PICRUSt2 prediction results for the different sample types (FG, EG, FP2h, FP24h, and SW) and feeding experiments. Predicted function abundances are provided (mean per sample type, total, and overall relative abundance - RA\%). For each experiment, predicted functions were grouped into energy, carbon, nitrogen, sulfur, phosphate, and other metabolisms.

\section{Appendix S2}

Figure S1. Microbial community structure of the unfiltered dataset. All three experiments are included in the same analysis. Sample types: doliolids (FG and EG), fecal pellets (FP2h and FP24h), seawater (SW), and controls. The nMDS ordination is based on the Bray-Curtis similarity constructed from the relative abundance of ASVs (square root transformed).

Figure S2. Venn diagram showing the number of unique (highlighted in bold) and shared ASVs among sample types for (A) experiment 1, (B) experiment 2, and (C) experiment 3. Doliolids: FG and EG, fecal pellets: FP2h and FP24h, seawater: SW.

Figure S3. Relative abundance of six dominant classes associated with doliolids (FG and EG), fecal pellets (FP2h and FP24h), and seawater (SW) samples in different feeding experiments (1-3). Relative abundance of taxa contributing to [?]5\% is displayed in the barplots. Phyla abbreviations as follows: Bacteroidota (Bact.), Cyanobacteria (Cyanob.), Planctomycetota (Planct.), Proteobacteria (Proteo.).

Figure S4. Heatmap of the most differentially abundant microbial taxa (genus level) across sample types (EG: empty gut, FG: full gut, FP24h: fecal pellet 24h, FP2h: fecal pellet $2 \mathrm{~h}, \mathrm{SW}$ : seawater) and experiments (1-3). Taxon abundance was transformed using the centered-log ratio (CLR). For each taxon, warm colors indicate high abundance whereas cold colors indicate low abundance. A complete list of taxa differentially abundant for each taxonomic rank across sample types is provided in Table S6.

Figure S5. Microbial community composition associated with doliolids (FG and EG), fecal pellets (FP2h and FP24h), and seawater (SW) samples in different feeding experiments (1-3). Taxonomy of the 19 most abundant bacterial families (A) and genera (B) are given. Low abundance taxa were grouped into the "Others" category. Relative abundance of taxa contributing to [?] $5 \%$ is displayed in the barplots.

Figure S6. Heatmap of the most differentially abundant predicted functional genes (top 100) across sample types (EG: empty gut, FG: full gut, FP24h: fecal pellet 24h, FP2h: fecal pellet $2 \mathrm{~h}$, SW: seawater) and experiments (1-3). The abundance of different functions/genes was transformed using the centered-log ratio (CLR). Warm colors indicate high abundance whereas cold colors indicate low abundance. A complete list of functions/genes differentially abundant, including their description, for each experiment and across sample types is provided in Table $\mathrm{S} 7$.

Figure S7. nMDS based on differentially abundant predicted functional genes according to experiment (A: experiment 1, B: experiment 2, C: experiment 3) and sample types: doliolids (FG and EG), fecal pellets (FP2h and FP24h), and seawater (SW). The nMDS ordination is based on the Bray-Curtis similarity constructed from the relative abundance of predicted functional genes (square root transformed) identified by $A L D E x 2$. 


\section{REFERENCES}

Alldredge, A. L., \& Madin, L. P. (1982). Pelagic tunicates: unique herbivores in the marine plankton.Bioscience,32(8), 655-663. https://doi.org/10.2307/1308815

Allen, A. E., Booth, M. G., Verity, P. G., \& Frischer, M. E. (2005). Influence of nitrate availability on the distribution and abundance of heterotrophic bacterial nitrate assimilation genes in the Barents Sea during summer.Aquatic Microbial Ecology: International Journal,39, 247-255. https://doi.org/10.3354/ame039247

Anderson, M., Gorley, R., \& Clarke, K. P. (2008). for PRIMER: guide to software and statistical methods.Primer-E, Plymouth, UK.

Apprill, A., McNally, S., Parsons, R., \& Weber, L. (2015). Minor revision to V4 region SSU rRNA 806R gene primer greatly increases detection of SAR11 bacterioplankton. Aquatic Microbial Ecology: International Journal,75 (2), 129-137. https://doi.org/10.3354/ame01753

Benjamini, Y., \& Hochberg, Y. (1995). Controlling the false discovery rate: a practical and powerful approach to multiple testing. Journal of the Royal Statistical Society: Series B (Methodological),57(1), 289300. https://doi.org/10.1111/j.2517-6161.1995.tb02031.x

Berger, A., Blackwelder, P., Frank, T., Sutton, T. T., Pruzinsky, N. M., Slayden, N., \& Lopez, J. V. (2021). Microscopic and genetic characterization of bacterial symbionts with bioluminescent potential in Pyrosoma atlanticum.Frontiers in Marine Science,8. https://doi.org/10.3389/fmars.2021.606818

Boero, F., Bouillon, J., Gravili, C., Miglietta, M. P., Parsons, T., \& Piraino, S. (2008). Gelatinous plankton: irregularities rule the world (sometimes).Marine Ecology Progress Series,356, 299-310. https://doi.org/10.3354/meps07368

Bolyen, E., Rideout, J. R., Dillon, M. R., Bokulich, N. A., Abnet, C. C., Al-Ghalith, G. A., Alexander, H., Alm, E. J., Arumugam, M., Asnicar, F., Bai, Y., Bisanz, J. E., Bittinger, K., Brejnrod, A., Brislawn, C. J., Brown, C. T., Callahan, B. J., Caraballo-Rodríguez, A. M., Chase, J., . . Caporaso, J. G. (2019). Reproducible, interactive, scalable and extensible microbiome data science using QIIME 2.Nature Biotechnology,37(8), 852-857. https://doi.org/10.1038/s41587-019-0209-9

Boscaro, V., Holt, C. C., Van Steenkiste, N. W. L., Herranz, M., Irwin, N. A. T., Àlvarez-Campos, P., Grzelak, K., Holovachov, O., Kerbl, A., Mathur, V., Okamoto, N., Piercey, R. S., Worsaae, K., Leander, B. S., \& Keeling, P. J. (2022). Microbiomes of microscopic marine invertebrates do not reveal signatures of phylosymbiosis.Nature Microbiology,7(6), 810-819. https://doi.org/10.1038/s41564-022-01125-9

Bosi, E., Fondi, M., Orlandini, V., Perrin, E., Maida, I., de Pascale, D., Tutino, M. L., Parrilli, E., Lo Giudice, A., Filloux, A., \& Fani, R. (2017). The pangenome of (Antarctic)Pseudoalteromonasbacteria: evolutionary and functional insights.BMC Genomics,18(1), 93. https://doi.org/10.1186/s12864-016-3382-y

Burke, C., Steinberg, P., Rusch, D., Kjelleberg, S., \& Thomas, T. (2011). Bacterial community assembly based on functional genes rather than species.Proceedings of the National Academy of Sciences of the United States of America,108(34), 14288-14293. https://doi.org/10.1073/pnas.1101591108

Callahan, B. J., McMurdie, P. J., Rosen, M. J., Han, A. W., Johnson, A. J. A., \& Holmes, S. P. (2016). DADA2: High-resolution sample inference from Illumina amplicon data.Nature Methods,13(7), 581-583. https://doi.org/10.1038/nmeth.3869

Camacho, C., Coulouris, G., Avagyan, V., Ma, N., Papadopoulos, J., Bealer, K., \& Madden, T. L. (2009). BLAST : architecture and applications. InBMC Bioinformatics(Vol. 10, Issue 1, p. 421). https://doi.org/10.1186/1471-2105-10-421

Caporaso, J. G., Lauber, C. L., Walters, W. A., Berg-Lyons, D., Huntley, J., Fierer, N., Owens, S. M., Betley, J., Fraser, L., Bauer, M., Gormley, N., Gilbert, J. A., Smith, G., \& Knight, R. (2012). Ultra-high-throughput 
microbial community analysis on the Illumina HiSeq and MiSeq platforms. The ISME Journal,6(8), 16211624. https://doi.org/10.1038/ismej.2012.8

Choi, D. H., \& Cho, B. C. (2006).Shimia marinagen. nov., sp. nov., a novel bacterium of theRoseobacterclade isolated from biofilm in a coastal fish farm. International Journal of Systematic and Evolutionary Microbiology,56 (Pt 8), 1869-1873. https://doi.org/10.1099/ijs.0.64235-0

Clarke, K. R. (1993). Non-parametric multivariate analyses of changes in community structure.Australian Journal of Ecology,18(1), 117-143.https://onlinelibrary.wiley.com/doi/pdf/10.1111/j.1442-9993. 1993.tb00438.x

Condon, R. H., Steinberg, D. K., del Giorgio, P. A., Bouvier, T. C., Bronk, D. A., Graham, W. M., \& Ducklow, H. W. (2011). Jellyfish blooms result in a major microbial respiratory sink of carbon in marine systems.Proceedings of the National Academy of Sciences of the United States of America,108(25), 1022510230. https://doi.org/10.1073/pnas.1015782108

Conley, K. R., Lombard, F., \& Sutherland, K. R. (2018). Mammoth grazers on the ocean's minuteness: a review of selective feeding using mucous meshes.Proceedings. Biological Sciences / The Royal Society,285(1878). https://doi.org/10.1098/rspb.2018.0056

Cottrell, M. T., Wood, D. N., Yu, L., \& Kirchman, D. L. (2000). Selected chitinase genes in cultured and uncultured marine bacteria in the alpha- and gamma-subclasses of the proteobacteria.Applied and Environmental Microbiology,66(3), 1195-1201. https://doi.org/10.1128/AEM.66.3.1195-1201.2000

Coutinho, F. H., von Meijenfeldt, F. A. B., Walter, J. M., Haro-Moreno, J. M., Lopéz-Pérez, M., van Verk, M. C., Thompson, C. C., Cosenza, C. A. N., Appolinario, L., Paranhos, R., Cabral, A., Dutilh, B. E., \& Thompson, F. L. (2021). Ecogenomics and metabolic potential of the South Atlantic Ocean microbiome. The Science of the Total Environment,765, 142758. https://doi.org/10.1016/j.scitotenv.2020.142758

Crocker, K. M., Alldredge, A. L., \& Steinberg, D. K. (1991). Feeding rates of the doliolid,Dolioletta gegenbauri, on diatoms and bacteria.Journal of Plankton Research,13(1), 77-82. https://doi.org/10.1093/plankt/13.1.77

Daley, M. C., Urban-Rich, J., \& Moisander, P. H. (2016). Bacterial associations with the hydromedusaNemopsis bacheiand scyphomedusaAurelia auritafrom the North Atlantic Ocean.Marine Biology Research,12(10), 1088-1100. https://doi.org/10.1080/17451000.2016.1228974

Daniels, C., \& Breitbart, M. (2012). Bacterial communities associated with the ctenophoresMnemiopsis leidyiandBeroe ovata.FEMS Microbiology Ecology,82(1), 90-101. https://doi.org/10.1111/j.15746941.2012.01409.x

Datta, M. S., Almada, A. A., Baumgartner, M. F., Mincer, T. J., Tarrant, A. M., \& Polz, M. F. (2018). Inter-individual variability in copepod microbiomes reveals bacterial networks linked to host physiology. The ISME Journal,12(9), 2103-2113. https://doi.org/10.1038/s41396-018-0182-1

Davis, N. M., Proctor, D. M., Holmes, S. P., Relman, D. A., \& Callahan, B. J. (2018). Simple statistical identification and removal of contaminant sequences in marker-gene and metagenomics data.Microbiome,6(1), 226. https://doi.org/10.1186/s40168-018-0605-2

Décima, M., Stukel, M. R., Nodder, S. D., Gutiérrez-Rodríguez, A., Selph, K. E., dos Santos, A. L., Safi, K., Kelly, T. B., Deans, F., Morales, S. E., Baltar, F., Latasa, M., Gorbunov, M. Y., \& Pinkerton, M. (in review). Salp blooms increase carbon export 5-fold in the Southern Ocean. Nature Communications.https: //doi.org/10.1101/2022.02.07.479467

De Corte, D., Srivastava, A., Koski, M., Garcia, J. A. L., Takaki, Y., Yokokawa, T., Nunoura, T., Elisabeth, N. H., Sintes, E., \& Herndl, G. J. (2018). Metagenomic insights into zooplankton-associated bacterial communities.Environmental Microbiology,20(2), 492-505. https://doi.org/10.1111/1462-2920.13944 
Deibel, D. (1985). Blooms of the pelagic tunicate,Dolioletta gegenbauri: Are they associated with Gulf Stream frontal eddies? Journal of Marine Research,43(1), 211-236. https://doi.org/10.1357/002224085788437307

Deibel, D. (1998). The abundance, distribution, and ecological impact of doliolids. In Q. Bone (Ed.), The Biology of Pelagic Tunicates(pp. 171-186). Oxford University Press.https://ci.nii.ac.jp/ naid/10012657566/

Deibel, D., \& Lowen, B. (2011). A review of the life cycles and life-history adaptations of pelagic tunicates to environmental conditions.ICES Journal of Marine Science: Journal Du Conseil,69(3), 358-369. https://doi.org/10.1093/icesjms/fsr159

Douglas, G. M., Maffei, V. J., Zaneveld, J. R., Yurgel, S. N., Brown, J. R., Taylor, C. M., Huttenhower, C., \& Langille, M. G. I. (2020). PICRUSt2 for prediction of metagenome functions.Nature Biotechnology,38(6), 685-688. https://doi.org/10.1038/s41587-020-0548-6

Fernandes, A. D., Macklaim, J. M., Linn, T. G., Reid, G., \& Gloor, G. B. (2013). ANOVA-like differential expression (ALDEx) analysis for mixed population RNA-Seq.PloS One,8(7), e67019. https://doi.org/10.1371/journal.pone.0067019

Fernandes, A. D., Reid, J. N., Macklaim, J. M., McMurrough, T. A., Edgell, D. R., \& Gloor, G. B. (2014). Unifying the analysis of high-throughput sequencing datasets: characterizing RNA-seq, 16S rRNA gene sequencing and selective growth experiments by compositional data analysis. Microbiome,2, 15. https://doi.org/10.1186/2049-2618-2-15

Frischer, M. E., Lamboley, L. M., Walters, T. L., Brandes, J. A., Arneson, E., Lacy, L. E., LópezFigueroa, N. B., Rodriguez-Santiago, A. E., \& Gibson, D. M. (2021). Selective feeding and linkages to the microbial food web by the doliolidDolioletta gegenbauri.Limnology and Oceanography,66(5), 1993-2010. https://doi.org/10.1002/lno.11740

Gasol, J. M., \& Kirchman, D. L. (Eds.). (2018).Microbial ecology of the oceans(3rd ed.). Wiley Blackwell.

Gibson, D. M., \& Paffenhofer, G.-A. (2000). Feeding and growth rates of the doliolid,Dolioletta gegenbauriUljanin (Tunicata, Thaliacea).Journal of Plankton Research,22(8), 1485-1500. https://doi.org/10.1093/plankt/22.8.1485

Giovannoni, S. J. (2017). SAR11 Bacteria: the most abundant plankton in the oceans. Annual Review of Marine Science,9, 231-255. https://doi.org/10.1146/annurev-marine-010814-015934

Greer, A. T., Chiaverano, L. M., Treible, L. M., Briseno-Avena, C., \& Hernandez, F. J. (2021). From spatial pattern to ecological process through imaging zooplankton interactions.ICES Journal of Marine Science: Journal Du Conseil,78(8), 2664-2674. https://doi.org/10.1093/icesjms/fsab149

Greer, A. T., Schmid, M. S., Duffy, P. I., Robinson, K. L., Genung, M. A., Luo, J. Y., Panaiotis, T, BrisenoAvena, C, Frischer, M. E., Sponaugle, S., \& Cowen, R. K. (submitted). In situ imaging across ecosystems to resolve the fine-scale oceanographic drivers of a globally significant planktonic grazer.Limnology and Oceanography.

Hao, W., Gerdts, G., Holst, S., \& Wichels, A. (2019). Bacterial communities associated with scyphomedusae at Helgoland Roads.Marine Biodiversity,49(3), 1489-1503. https://doi.org/10.1007/s12526-018-0923-4

Holmstrom, C., \& Kjelleberg, S. (1999). MarinePseudoalteromonasspecies are associated with higher organisms and produce biologically active extracellular agents.FEMS Microbiology Ecology,30(4), 285-293. https://doi.org/10.1111/j.1574-6941.1999.tb00656.x

Jaspers, C., Weiland-Brauer, N., Ruhlemann, M. C., Baines, J. F., Schmitz, R. A., \& Reusch, T. B. H. (2020). Differences in the microbiota of native and non-indigenous gelatinous zooplankton organisms in a low saline environment. The Science of the Total Environment,734, 139471. https://doi.org/10.1016/j.scitotenv.2020.139471 
Klappenbach, J. A., Saxman, P. R., Cole, J. R., \& Schmidt, T. M. (2001). rrndb: the Ribosomal RNA Operon Copy Number Database.Nucleic Acids Research,29(1), 181-184. https://doi.org/10.1093/nar/29.1.181

Kos Kramar, M., Tinta, T., Lučić, D., Malej, A., \& Turk, V. (2019). Bacteria associated with moon jellyfish during bloom and post-bloom periods in the Gulf of Trieste (northern Adriatic).PloS One,14(1), e0198056. https://doi.org/10.1371/journal.pone.0198056

Köster, M., \& Paffenhöfer, G.-A. (2017). How efficiently can doliolids (Tunicata, Thaliacea) utilize phytoplankton and their own fecal pellets? Journal of Plankton Research,39(2), 305-315. https://doi.org/10.1093/plankt/fbw089

Köster, M., Sietmann, R., Meuche, A., \& Paffenhöfer, G.-A. (2011). The ultrastructure of a doliolid and a copepod fecal pellet.Journal of Plankton Research,33(10), 1538-1549. https://doi.org/10.1093/plankt/fbr053

Kuypers, M. M. M., Marchant, H. K., \& Kartal, B. (2018). The microbial nitrogen-cycling network.Nature Reviews. Microbiology,16(5), 263-276. https://doi.org/10.1038/nrmicro.2018.9

Lebrato, M., Pahlow, M., Frost, J. R., \& Küter, M. (2019). Sinking of gelatinous zooplankton biomass increases deep carbon transfer efficiency globally. Global Biogeochemical Cycles,33, 1764-1783.https: //agupubs. onlinelibrary.wiley.com/doi/abs/10.1029/2019GB006265

Lucas, C. H., \& Dawson, M. N. (2014). What are jellyfishes and thaliaceans and why do they bloom? In K. A. Pitt \& C. H. Lucas (Eds.), Jellyfish Blooms(pp. 9-44). Springer Netherlands. https://doi.org/10.1007/97894-007-7015-7_2

Lu, X., Sun, S., Zhang, Y.-Q., Hollibaugh, J. T., \& Mou, X. (2015). Temporal and vertical distributions of bacterioplankton at the Gray's Reef National Marine Sanctuary. Applied and Environmental Microbiology,81(3), 910-917. https://doi.org/10.1128/AEM.02802-14

Martin, M. (2011). Cutadapt removes adapter sequences from high-throughput sequencing reads.EMBnet.journal,17(1), 10. https://doi.org/10.14806/ej.17.1.200

McMurdie, P. J., \& Holmes, S. (2013). phyloseq: an R package for reproducible interactive analysis and graphics of microbiome census data.PloS One,8(4), e61217. https://doi.org/10.1371/journal.pone.0061217

Paffenhöfer, G. A., \& Köster, M. (2005). Digestion of diatoms by planktonic copepods and doliolids.Marine Ecology Progress Series,297, 303-310. https://doi.org/10.3354/meps297303

Parada, A. E., Needham, D. M., \& Fuhrman, J. A. (2016). Every base matters: assessing small subunit rRNA primers for marine microbiomes with mock communities, time series and global field samples. Environmental Microbiology,18(5), 1403-1414. https://doi.org/10.1111/1462-2920.13023

Patonai, K., El-Shaffey, H., \& Paffenhöfer, G.-A. (2011). Sinking velocities of fecal pellets of doliolids and calanoid copepods. Journal of Plankton Research,33(7), 1146-1150. https://doi.org/10.1093/plankt/fbr011

Perissinotto, R., \& Pakhomov, E. A. (1998). Contribution of salps to carbon flux of marginal ice zone of the Lazarev Sea, Southern Ocean.Marine Biology,131(1), 25-32. https://doi.org/10.1007/s002270050292

Pomeroy, L. R., \& Deibel, D. (1980). Aggregation of organic matter by pelagic tunicates.Limnology and Oceanography,25(4), 643-652. https://doi.org/10.4319/lo.1980.25.4.0643

Quast, C., Pruesse, E., Yilmaz, P., Gerken, J., Schweer, T., Yarza, P., Peplies, J., \& Glöckner, F. O. (2013). The SILVA ribosomal RNA gene database project: improved data processing and web-based tools. Nucleic Acids Research,41(Database issue), D590-D596. https://doi.org/10.1093/nar/gks1219

$\mathrm{R}$ Core Team. (2021).R: A language and environment for statistical computing(Version 4.1.2). R Foundation for Statistical Computing, Vienna, Austria.https://www.R-project.org 
Scavotto, R. E., Dziallas, C., Bentzon-Tilia, M., Riemann, L., \& Moisander, P. H. (2015). Nitrogen-fixing bacteria associated with copepods in coastal waters of the North Atlantic Ocean.Environmental Microbiology,17(10), 3754-3765. https://doi.org/10.1111/1462-2920.12777

Schauer, M., Balagué, V., Pedrós-Alió, C., \& Massana, R. (2003). Seasonal changes in the taxonomic composition of bacterioplankton in a coastal oligotrophic system. Aquatic Microbial Ecology: International Journal,31, 163-174. https://doi.org/10.3354/ame031163

Schuelke, T., Pereira, T. J., Hardy, S. M., \& Bik, H. M. (2018). Nematode-associated microbial taxa do not correlate with host phylogeny, geographic region or feeding morphology in marine sediment habitats.Molecular Ecology,27(8), 1930-1951. https://doi.org/10.1111/mec.14539

Shoemaker, K. M., Duhamel, S., \& Moisander, P. H. (2019). Copepods promote bacterial community changes in surrounding seawater through farming and nutrient enrichment.Environmental Microbiology,21(10), 37373750. https://doi.org/10.1111/1462-2920.14723

Silva, M. A. C. da, da Silva, M. A. C., \& de Souza Lima, A. O. (2017). Diversity and prospection of South Atlantic Ocean microorganisms. In J. L. De Azevedo \& M. C. Quecine (Eds.),Diversity and benefits of microorganisms from the tropics. Springer.(pp. 105-136). Springer. https://doi.org/10.1007/978-3-31955804-2_6

Smetacek, V., Assmy, P., \& Henjes, J. (2004). The role of grazing in structuring Southern Ocean pelagic ecosystems and biogeochemical cycles.Antarctic Science / Blackwell Scientific Publications,16(4), 541-558. https://doi.org/10.1017/S0954102004002317

Stukel, M. R., Décima, M., Selph, K. E., \& Gutiérrez-Rodríguez, A. (2021). Size-specific grazing and competitive interactions between large salps and protistan grazers.Limnology and Oceanography,66 (6), 25212534. https://doi.org/10.1002/lno.11770

Suarez-Moo, P., Cruz-Rosales, M., Ibarra-Laclette, E., Desgarennes, D., Huerta, C., \& Lamelas, A. (2020). Diversity and composition of the gut Microbiota in the developmental stages of the dung beetleCopris incertusSay (Coleoptera, Scarabaeidae). InFrontiers in Microbiology(Vol. 11). https://doi.org/10.3389/fmicb.2020.01698

Sun, S., Jones, R. B., \& Fodor, A. A. (2020). Inference-based accuracy of metagenome prediction tools varies across sample types and functional categories.Microbiome,8(1), 46. https://doi.org/10.1186/s40168020-00815-y

Takahashi, K., Ichikawa, T., Fukugama, C., Yamane, M., Kakehi, S., Okazaki, Y., Kubota, H., \& Furuya, K. (2015). In situ observations of a doliolid bloom in a warm water filament using a video plankton recorder: Bloom development, fate, and effect on biogeochemical cycles and planktonic food webs.Limnology and Oceanography,60(5), 1763-1780. https://doi.org/10.1002/lno.10133

Tang, K. (2020). Chemical diversity and biochemical transformation of biogenic organic sulfur in the ocean.Frontiers in Marine Science,7. https://doi.org/10.3389/fmars.2020.00068

Tang, K. W., Backhaus, L., Riemann, L., Koski, M., Grossart, H.-P., Munk, P., \& Nielsen, T. G. (2019). Copepod carcasses in the subtropical convergence zone of the Sargasso Sea: implications for microbial community composition, system respiration and carbon flux. Journal of Plankton Research,41(4), 549-560. https://doi.org/10.1093/plankt/fbz038

Tebeau, C. M., \& Madin, L. P. (1994). Grazing rates for three life history stages of the doliolidDolioletta gegenbauriUljanin (Tunicata, Thaliacea). Journal of Plankton Research,16(8), 1075-1081. https://doi.org/10.1093/plankt/16.8.1075

Thome, P. E., \& Rivera-Ortega, J. (2022). Specific antibacterial activity against potential pathogens and restraining of larvae settlement from a pigmentedPseudoalteromonasstrain isolated from the jellyfish ...International Aquatic Research,14, 95-105. https://doi.org/10.22034/IAR.2022.1946683.1218 
Thompson, A. W., Ward, A. C., Sweeney, C. P., \& Sutherland, K. R. (2021). Host-specific symbioses and the microbial prey of a pelagic tunicate (Pyrosoma atlanticum).ISME Communications,1(1), 1-10. https://doi.org/10.1038/s43705-021-00007-1

Tinta, T., Klun, K., \& Herndl, G. J. (2021). The importance of jellyfish-microbe interactions for biogeochemical cycles in the ocean.Limnology and Oceanography,66 (5), 2011-2032. https://doi.org/10.1002/lno.11741

Tinta, T., Kogovšek, T., Klun, K., Malej, A., Herndl, G. J., \& Turk, V. (2019). Jellyfish-associated microbiome in the marine environment: exploring its biotechnological potential.Marine Drugs,17(2). https://doi.org/10.3390/md17020094

Vargas, C. A., \& Madin, L. P. (2004). Zooplankton feeding ecology: clearance and ingestion rates of the salps Thalia democratica, Cyclosalpa affinisandSalpa cylindricaon naturally occurring particles in the MidAtlantic Bight. Journal of Plankton Research,26(7), 827-833. https://doi.org/10.1093/plankt/fbh068

Viver, T., Orellana, L. H., Hatt, J. K., Urdiain, M., Díaz, S., Richter, M., Antón, J., Avian, M., Amann, R., Konstantinidis, K. T., \& Rosselló-Móra, R. (2017). The low diverse gastric microbiome of the jellyfish Cotylorhiza tuberculatais dominated by four novel taxa.Environmental Microbiology,19(8), 3039-3058. https://doi.org/10.1111/1462-2920.13763

Voogd, N. J. de, de Voogd, N. J., Cleary, D. F. R., Polónia, A. R. M., \& Gomes, N. C. M. (2015). Bacterial community composition and predicted functional ecology of sponges, sediment and seawater from the thousand islands reef complex, West Java, Indonesia. InFEMS Microbiology Ecology(Vol. 91, Issue 4). https://doi.org/10.1093/femsec/fiv019

Walters, T. L., Gibson, D. M., \& Frischer, M. E. (2019). Cultivation of the marine pelagic tunicateDolioletta gegenbauri(Uljanin 1884) for experimental studies.Journal of Visualized Experiments: JoVE,150. https://doi.org/10.3791/59832

Walters, T. L., Lamboley, L. M., López-Figueroa, N. B., Rodríguez-Santiago, Á. E., Gibson, D. M., \& Frischer, M. E. (2019). Diet and trophic interactions of a circumglobally significant gelatinous marine zooplankter,Dolioletta gegenbauri(Uljanin, 1884).Molecular Ecology,28(2), 176-189. https://doi.org/10.1111/mec.14926

Wickham, H. (2016).ggplot2: Elegant graphics for data analysis. Springer.

Yilmaz, P., Yarza, P., Rapp, J. Z., \& Glöckner, F. O. (2015). Expanding the world of marine bacterial and archaeal clades.Frontiers in Microbiology,6 , 1524. https://doi.org/10.3389/fmicb.2015.01524

Zar, J. H. (2010).Biostatistical analysis(5th ed., p. 71). Pearson Prentice-Hall.

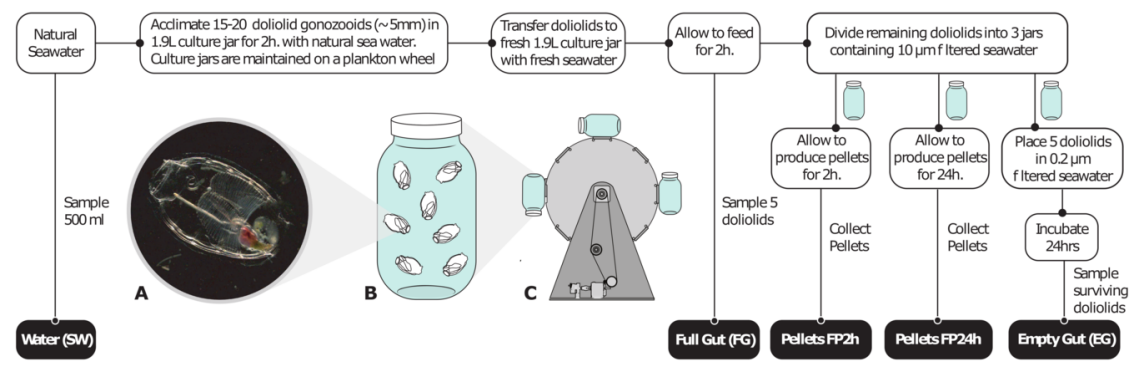




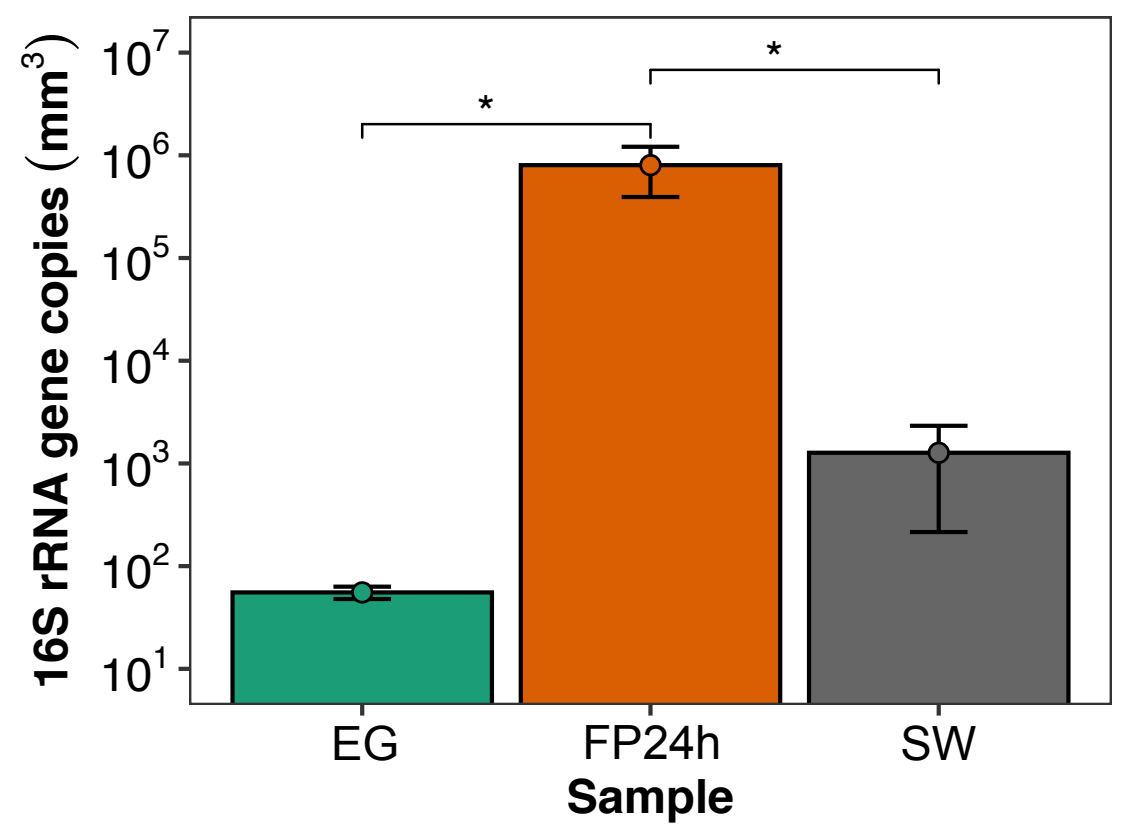




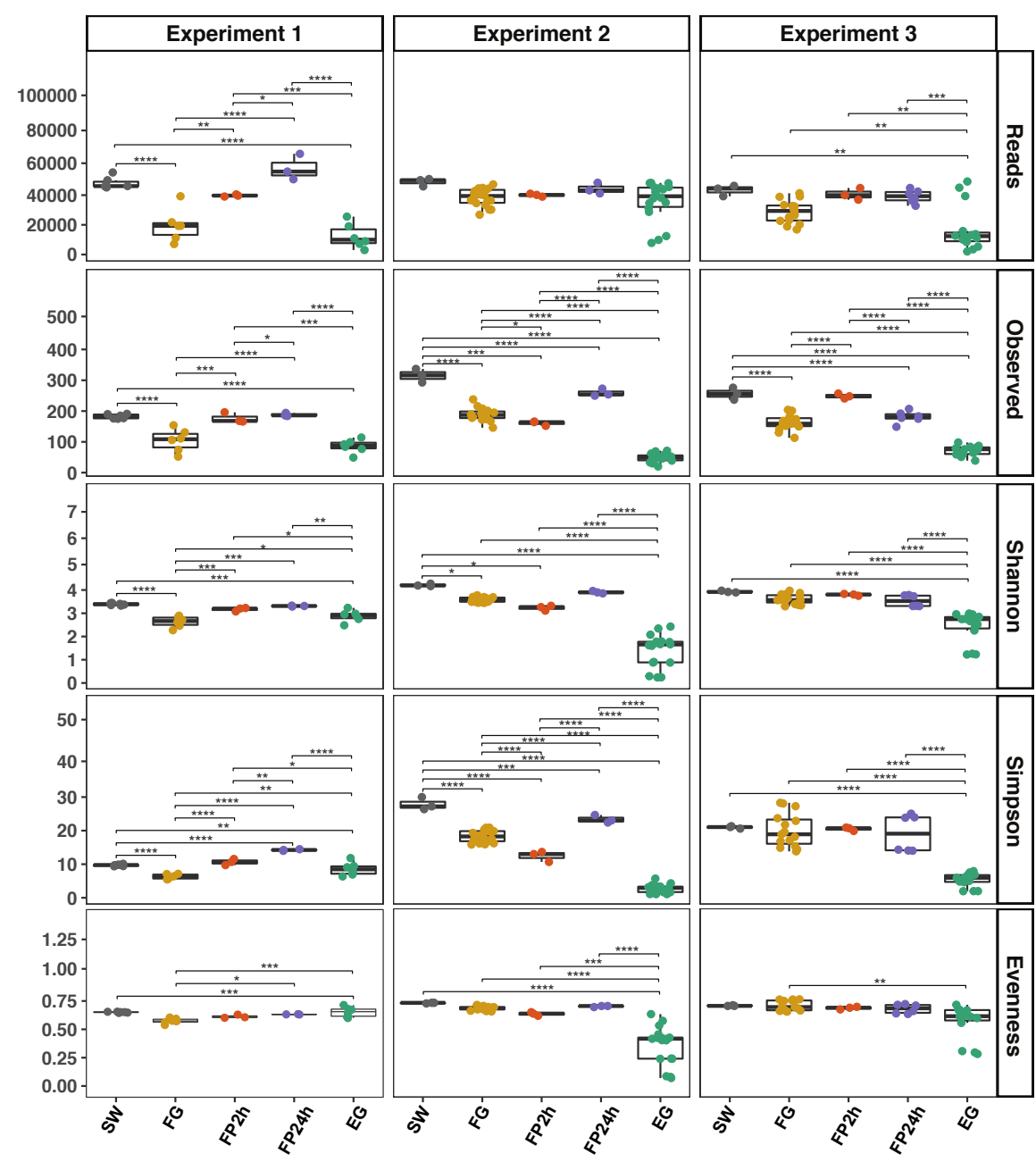

Sample 


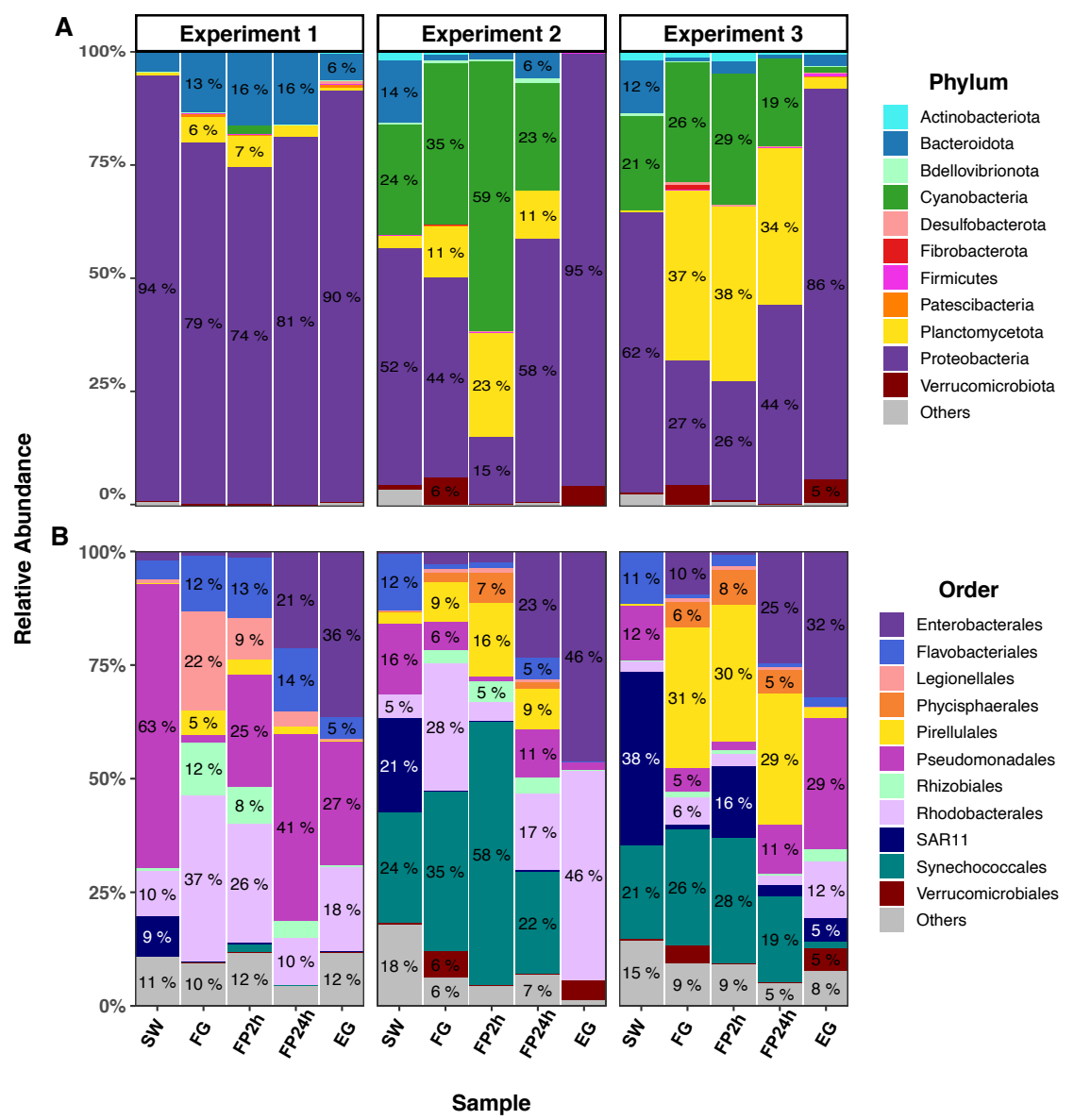



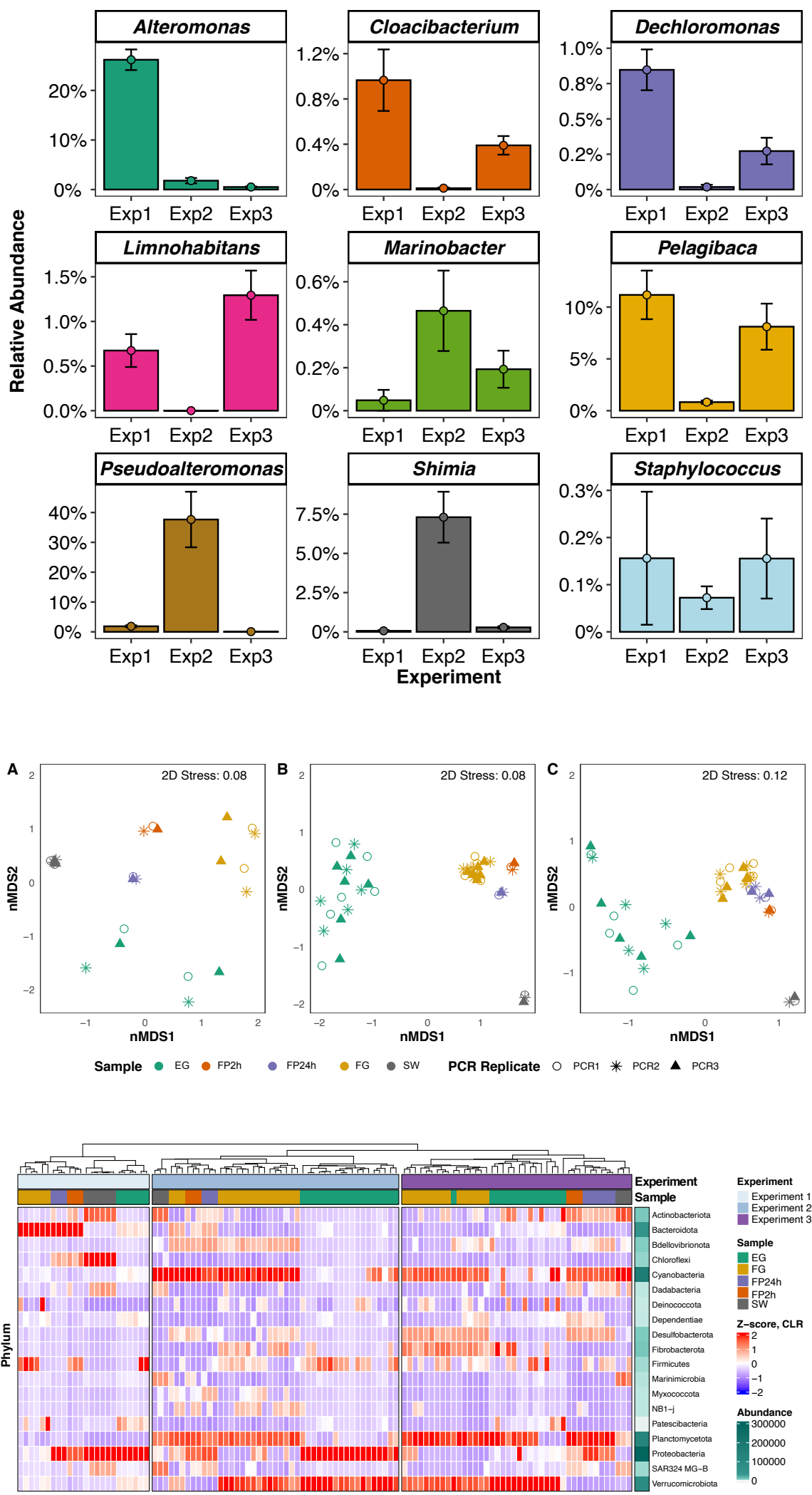


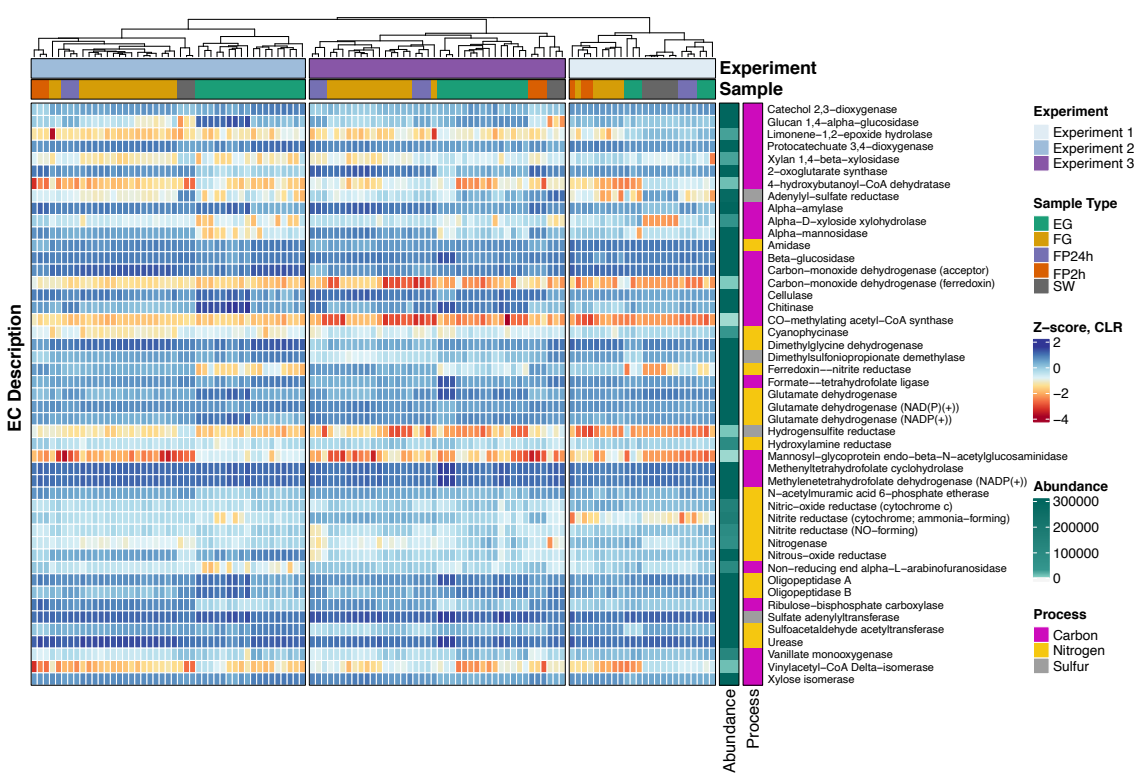

